\title{
Combating Global Burden of Obesity: Issues and Challenges
}

\author{
Anisa M Durrani* \\ Department of Home Science, Aligarh Muslim University, India
}

Submission: March 20, 2018; Published: April 26, 2018

*Corresponding author: Anisa M Durrani, Department of Home Science, Aligarh Muslim University, India, Email: anisamd@gmail.com

\begin{abstract}
Almost at global plane every county is facing different transitional stages in terms of demographic, socio economic and physical development. This developmental transition is causing far reaching changes and affecting the lives of millions of people. Invention of energy saving devices and sedentary occupations have contributed to striking change in the morbidity profile of the population. Chronic degenerative disease including obesity are now emerging as major causes of morbidity and mortality. As a result the prevalence of global obesity has tripled since 1975 and has reached endemic proportion all over the world. World Health Organisation (2018) reported more than 1.9 billion adults were over weight in 2016, and of these 650 million were obese [1]. Recommended weight reduction treatments are disappointing and of limited value. The relationship between physical inactivity and obesity is however complex, consequently giving rise to confusion and further complicate the picture such as physical fitness, opportunities for exercise, diet and the temporal relationship between physical activity and meals. In this study, the role of adequate regular physical exercise and sustained dietary discipline have been discussed and reviewed.
\end{abstract}

Keywords: Obesity; Physical activity; Overweight; Exercise; Weight reduction treatment

\section{Introduction}

Obesity is essentially a disorder of energy balance characterized by an excess of body fat. The amount of fat in the adipose tissue is the sum total of the difference between food/energy intake and energy expenditure. Energy balance is controlled by energy intake and expenditure mediated through endocrinal (hormonal) nutrient, neurological. gastrointestinal and metabolic signals, all these processed by the central nervous system.

Obesity with increasing prevalence in adults and children is a leading preventable cause of death worldwide. Experts view it as one of the most serious global health problems of the 21st century. In 2013, the American Medical Association classified obesity as a disease [2]. Once considered a problem only of highincome countries, obesity rates are now rising worldwide and affecting both the developed and developing countries alike. The last three decades have witnessed scaling up of the prevalence of over weigh and obesity. This global health affecting trend is discernable in all societies irrespective of their socio economic conditions. Discrete projections indicate that the situation will continue to remain alarming in the near future also [3]. In view of its far reaching consequences, obesity has presumed as a major public health concern. It is chronic in nature, and often associated with a wide range of metabolic abnormalities and degenerative diseases, some of which could be life threatening diseases such as cardio vascular diseases, certain categories of cancer and type 2 diabetes. It is also observed that the mortality is directly proportional to the degree of obesity [4] and undoubtedly there is a need to reverse this life threatening modern epidemic. It is felt that the result of current method of treating are disappointing and of limited value. Largely the government's initiatives are seem to be individual- centric with much emphasis on promoting consumption of balanced diet and physical exercise. But the ground reality is that sufficient access to healthier food and physical activities are severely lacking [5].

The crucial twin factors "restrictions of energy intake" and "maintenance of increased energy expenditure" are still in the never ending state of discussion and debate. This has resulted in a climate of confusion, dampening the utilitarian dimensions of physical activity (PA) as a remedial measure to achieve weight loss [6]. The media discourses also zealously depict the uselessness of physical exercise in restraining obesity has further added perplexity. The answer lies in prevention. So a systematic review has been done to consider the role of regular physical exercise and sustained dietary discipline

\section{Life style changes are paving way for decline in physical activity}

Obesity is basically a disorder of energy balance triggered by excess body fat, in which the amount of body fat exceeds the biological need of an individual. The amount of body fat ultimately is influenced by age, gender, composition of diet, 
and level of social, cultural and behavioral factors which act on physiological and biochemical mechanisms that dictate food intake and energy expenditure. Small deviation in total energy intake and expenditure over an extended period of time will result in body weight gain. This may be the reason why obesity has spread inexorably across the world with rapid speed.

Beside in the last fifty years, human civilization witnessed enormous technological strides in almost every sphere of human endeavors, including the most profound impact that digitalization has brought in our living situations. These developments have also impacted our daily energy expenditure. A recent US study reveals that during the past fifty years energy expenditure for work has radically declined by over $100 \mathrm{kcal}$ both in male and female employees [7]. The decline is associated in the mean body weight among American population. Weight gain trend is not exclusive to the US. It appear to be the emerging salience of modern age. A study carried in Finland between 1982 and 1992 on daily energy expenditure in work place reveals a decline of more than $50 \mathrm{kcal}$ with a corresponding increase in the average body weight [8]. Several studies carried in recent times and in different socio economic settings shows almost the same results [9]. Decline in energy expenditure has also swept the developing countries like Brazil and China. These countries also have highest absolute and relative rates of energy expenditure reduction due to decline in work movements [10]. Based on these examples, conclusions were drawn that the low income countries are also getting severely affected by the epidemic of obesity. The urban and industrial cities and towns are likely to be more severely affected in the future [11]. Invention of machines in the cycle of domestic chores like cooking, grinding, sweeping, dusting and washing etc. with devices such as microwaves, cooking range, mixers, grinders and juicers and vacuum cleaners and washing machines and dish washers have radically brought down energy expenditure particularly in women. A study has revealed that since 1960's in US, women daily domestic routines have slide down by $360 \mathrm{kcal}$ [12]. On the bases of these figures conclusions were drawn that obesity in high income countries has been substantially increased due to steep reduction in house work energy expenditure [13]. Moreover, the automation of work at domestic level has enhanced sedentary engagements such as watching television, internet browsing, social media chatting, lazily idling etc. A number of studies considered these emerging sedentary behaviour as a major factor in increasing weight in individuals $[14,15]$. However there is a silver lining, some conscious social segments have now started to consciously participate in leisure- time physical activity. Although this group is comparatively small they are engaging in regular exercises, walking, running, yoga and sport engagement as well as keep fit gym based activities [16]. But on larger social scale, active physical engagements of a fraction of society cannot have a significant impact on the larger social mass involved in sedentary behaviour, thus contributing to the fast PA decline across globe.

\section{The relation between energy expenditure and obesity epidemic is contentious}

Some researchers are sceptic about the notion that body weight and obesity rise with reduction in daily energy expenditure. There are a set of evidences that contradicts the attribution of obesity to reduction in daily energy expenditure, It is argued that 'labour - saving' culture was in place since $1960 \mathrm{~s}$ and 1970s, on the other hand prevalence of obesity assumed alarming proportions only in 1980s. Similarly doubly- labelled water studies which are considered as most credible method to measure energy expenditure in individuals records no reduction in daily energy expenditure during 1980-2005 both in Europe and North America [17]. The meta analysis of about 100 doubly labelled water (DLW) studies also reveals that population in industrialized countries have similar daily expenditure without reduction when compared with their counter parts in developing countries [18]. It was found that obese individuals have a habit to spend higher energy expenditure than normal weight individuals this is because of their large body size and resting metabolic rate [19].

The studies carried by Leibel et al. [20] shows that $10 \%$ weight gain increases daily energy expenditure from $371-530 \mathrm{kcal}$. The natural fall out of this increase in energy expenditure is that the rate of energy intake need to rise to avoid weight loss [20]. Another study that contradict the notion of reduction in energy expenditure is by Swinburn et al. [21] which studied the US nutritional surveillance data spread between 1970s and 2000s. The study estimated an increase of $500 \mathrm{k}$ cal in the daily energy intake of average American adult. Several European studies have reported similar kcal increased intake trend [22,23]. A study by Archer et al. [24], reported a substantial difference in energy intake with the modification of measures of dietary intake as per the National Health and Nutrition Examination Survey (NHANES). One major problem that the researches confront is the inability to exactly quantify energy intake, where as energy expenditure can be precisely measurd [25]. Energy intake in human cannot be determined in precise measures namely due to selective misreporting on consumption pattern and this intake reporting bias introduce error in estimations [26]. In comparison a more reliable method which is existing is the national food availability data. This data indicates slow rise in energy intake in US until 1980s, then the period of rapid increase in energy intake was observed [27]. Likewise the global analyses also noticed the rise in the supplies of food- energy in high income countries, which testifies increase in average body weigh in the population.

\section{The impact of physical activity with dietary intake and weight control}

The primary cause of obesity may need not be low energy expenditure. But at the same time physical activities or exercise regime has its own significance in the management of weigh and maintenance of energy balance. A stream of scholars including 
the work of Mayer et al. \& Hill et al. [28,29], talk about a threshold with regard to PA about which people stays in "regulated zone" of energy balance. They argue that once people reach the regulated zone the process of balancing high energy expenditure with energy intake gets activated, ensuring the maintenance of body weight. The effect is inverse for those who fall short of PA threshold having low energy expenditure. While examining the relation between energy intake, PA, appetite and weight gain Shook et al. concluded that individuals with low PA had higher levels of cravings for foods in comparison to that of high PA [30]. They further noted a threshold for achieving energy balance which is about 7116 steps per day. The life cycle of individuals usually become sedentary after certain period of time, resulting in steeper rise in population weight gain.

Taking up exercise regime is a significant energy expenditure management technique that help to regulate energy balance. Hankinson et al. [31] in a 20 years of follow up longitudinal study concluded that high level of PA maintenance reduces significantly weight gain specially in women. The study also observe that active individual gain less weight in comparison the those who were inactive [31]. In line with above conclusions, Finish Twin Cohort who used natural experimental approach observes that physically active co-twins have significantly lower body weight [32], BMI and fat present, and they have much less about $50 \%$ visceral hepatic fat compared with their inactive twins. It signifies that persistent higher PA level is associated with decrease rate of weight gain irrespective of genetic liability control and environment factor. Numerous controlled experiments also emphasis the generation of energy deficit leads to induced weight loss [33]. The literature is full of reviews including the highly credible Cochrane Review that finds a strong correlation between exercise (PA) and weight loss. It also concludes that weight loss is even greater when energy restrictions are also included [34,35]. Hence one can easily conclude that both diet and exercise are supplementary and dependable instruments that help in measured weight loss.

In most cases long term weight loss programmes fails as an individual often gain weight again after some time. But there are studies which also shows when one is regularly consistence in diet and exercise regime, success in weight maintenance can also be achieved. It is clear that a worldwide emphasis must be placed on changing lifestyles, and this emphasis should include adherence to nutritional diet and, physical activity and avoidance of sedentary life style.

\section{Conclusion}

The health issues involved in obesity have now assumed the status of global challenge. Obesity is not only a problem of developed countries but is rapidly becoming a problem of developing countries as well. The problem of obesity once thought to be increasing with affluence, urbanization and industrialization are now spreading even in rural population. Apart from dietary errors, lack of regular physical exercise in the global population with sedentary occupations, is a major underlying factor. Increase in physical activity can certainly create energy deficit in individuals by enhancing energy expenditure. As physical inactivity and overweight are the major public health challenges of the 21st century, it is time to consider whether our public health surveillance systems are geared up in meeting these new challenge. The emerging need is to designed pragmatic strategies which promote both healthy dietary practices and regular physical activity in population ensuring access to healthy food and facilities that lead to physical activities and physical exercise.

\section{References}

1. World Health Organisation, Fact Sheet (2018) Obesity and Overweight, Media Centre.

2. Sudanese (2013) American medical Association Annual report content, 2013 summary, La Crosse, WI 54602-0038.

3. Finkelstein EA, Khavjou OA, Thompson H, Trogdon JG, Pan L, et al. (2012) Obesity and severe obesity forecasts through 2030. Am J Prev Med 42(6): 563-570.

4. Lu Y, Hajifathalian K, Ezzati M, Woodward M, Rimm EB, et al. (2014) Metabolic mediators of the effects of body-mass index, overweight, and obesity on coronary heart disease and stroke: a pooled analysis of 97 prospective cohorts with 1.8 million participants. Lancet 383(9921): 970-983.

5. Ng M, Fleming T, Robinson M, Thomson B, Graetz N, et al. (2014) Global, regional, and national prevalence of overweight and obesity in children and adults during 1980-2013: a systematic analysis for the Global Burden of Disease Study 2013. Lancet 384(9945): 766-781.

6. Hill JO, Peters JC (2013) Commentary: physical activity and weight control. Int J Epidemiol 42(6): 1840-1842.

7. Church TS, Thomas DM, Tudor Locke C, Katzmarzyk PT, Earnest CP, et al. (2011) Trends over 5 decades in U.S. occupation-related physical activity and their associations with obesity. PLoS One 6(5): e19657.

8. Fogelholm M, Männistö S, Vartiainen E, Pietinen P (1996) Determinants of energy balance and overweight in Finland 1982 and 1992. Int J Obes Relat Metab Disord 20(12): 1097-1104.

9. Borodulin K, Harald K, Jousilahti P, Laatikainen T, Männistö S, et al (2016) Time trends in physical activity from 1982 to 2012 in Finland. Scand J Med SciSports 26(1): 93-100.

10. Ng SW, Popkin BM (2012) Time use and physical activity: a shift away from movement across the globe. Obesity Rev 13(8): 659-680.

11. Prentice AM (2006) The emerging epidemic of obesity in developing countries. Int J Epidemiol 35(1): 93-99.

12. Archer E, Shook RP, Thomas DM, Church TS, Katzmarzyk PT, et al. (2013) 45-year trends in women's use of time and household management energy expenditure. PLoS One 8(2): e56620.

13. Lanningham Foster L, Nysse LJ, Levine JA (2003) Labor saved, calories lost: the energetic impact of domestic labor-saving devices. Obes Res 11(10): 1178-1181.

14. McCormack GR, Virk JS (2014) Driving towards obesity: a systematized literature review on the association between motor vehicle travel time and distance and weight status in adults. Prev Med 66: 49-55.

15. Rhodes RE, Mark RS, Temmel CP (2012) Adult sedentary behavior: a systematic review. Am J Prev Med 42(3): e3-e28.

16. Knuth AG, Hallal PC (2009) Temporal trends in physical activity: a systematic review. J Phys Act Health 6(5): 548-559. 


\section{Current Research in Diabetes \& Obesity Journal}

17. Westerterp KR, Speakman JR (2008) Physical activity energy expenditure has not declined since the 1980s and matches energy expenditures of wild mammals. Int J Obes (Lond) 32(8): 1256-1263.

18. Dugas LR, Harders R, Merrill S, Ebersole K, Shoham DA, et al. (2011) Energy expenditure in adults living in developing compared with industrialized countries: a meta-analysis of doubly labeled water studies. Am J Clin Nutr 93(2): 427-441.

19. Ravussin E, Burnand B, Schutz Y, Jéquier E (1982) Twenty-four-hour energy expenditure and resting metabolic rate in obese, moderately obese, and control subjects. Am J Clin Nutr 35(3): 566-573.

20. Leibel RL, Rosenbaum M, Hirsch J (1995) Changes in energy expenditure resulting from altered body weight. N Engl J Med 332(10) 621-628.

21. Swinburn B, Sacks G, Ravussin E (2009) Increased food energy supply is more than sufficient to explain the US epidemic of obesity. Am J Clin Nutr 90 (6): 1453-1456.

22. Silventoinen K, Sans S, Tolonen H, Monterde D, Kuulasmaa K, et al. (2004) Trends in obesity and energy supply in the WHO MONICA Project. Int J Obes Relat Metab Disord 28(5): 710-771.

23. Balanza R, García Lorda P, Pérez Rodrigo C, Aranceta J, Bonet MB, et al. (2007) Trends in food availability determined by the Food and Agriculture Organization's food balance sheets in Mediterranean Europe in comparison with other European areas. Public Health Nutr 10(2): 168-176.

24. Archer E, Hand GA, Blair SN (2013) Validity of U.S. nutritional surveillance: National Health and Nutrition Examination Survey caloric energy intake data, 1971-2010. PLoS One 8(10): e76632.

25. Black AE, Prentice AM, Goldberg GR, Jebb SA, Bingham SA, et al. (1993) Measurements of total energy expenditure provide insights into the validity of dietary measurements of energy intake. J Am Diet Assoc 93(5): 572-579.
26. Black AE, Cole TJ (2001) Biased over- or under-reporting is characteristic of individuals whether over time or by different assessment methods. J Am Diet Assoc 101(1): 70-80.

27. Levitsky DA, Pacanowski CR (2012) Free will and the obesity epidemic. Pblic Health Nutr 15(1): 126-141.

28. Mayer J, Roy P, Mitra KP (1956) Relation between caloric intake, body weight, and physical work: studies in an industrial male population in West Bengal. Am J Clin Nutr 4 (2): 169-175.

29. Hill JO, Wyatt HR, Peters JC (2012) Energy balance and obesity Circulation 126: 126-132

30. Shook RP, Hand GA, Drenowatz C, Hebert JR, Paluch AE, et al. (2015) Low levels of physical activity are associated with dysregulation of energy intake and fat mass gain over 1 year. Am J Clin Nutr 102(6): 1332-1338.

31. Hankinson AL, Daviglus ML, Bouchard C, Carnethon M, Lewis CE, et al. (2010) Maintaining a high physical activity level over 20 years and weight gain. JAMA 304 (23): 2603-2610.

32. Piirtola M, Kaprio J, Waller K, Heikkilä K, Koskenvuo M, et al. (2016) Leisure-time physical inactivity and association with body mass index: a Finnish Twin Study with a 35-year follow-up. Int J Epidemiol 46(1): 116-127.

33. Leskinen T, Sipilä S, Alen M, Cheng S, Pietiläinen KH, et al. (2009) Leisure-time physical activity and high-risk fat: a longitudinal population-based twin study Int J Obes (Lond) 33 (11): 1211-1218.

34. Donnelly JE, Honas JJ, Smith BK, Mayo MS, Gibson CA, et al. (2013) Aerobic exercise alone results in clinically significant weight loss for men and women: midwest exercise trial 2. Obesity (Silver Spring) 21(3): E219-E228.

35. Shaw K, Gennat H, O’Rourke P, Del Mar C (2006) Exercise for overweight or obesity Cochrane Database Syst Rev (4): CD003817.

\begin{tabular}{|l|}
\hline \multicolumn{1}{|c|}{ Your next submission with Juniper Publishers } \\
will reach you the below assets \\
- Quality Editorial service \\
- Swift Peer Review \\
- Reprints availability \\
- E-prints Service \\
- Manuscript Podcast for convenient understanding \\
- Global attainment for your research \\
- Manuscript accessibility in different formats \\
( Pdf, E-pub, Full Text, Audio) \\
- Unceasing customer service \\
Track the below URL for one-step submission \\
https://juniperpublishers.com/online-submission.php \\
\hline
\end{tabular}

